\title{
Family Economic Strain and Adolescent Aggression during the COVID-19 Pandemic: Roles of Interparental Conflict and Parent-Child Conflict
}

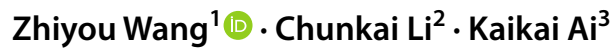

Received: 5 July 2021 / Accepted: 30 January 2022 / Published online: 7 February 2022

(C) The International Society for Quality-of-Life Studies (ISQOLS) and Springer Nature B.V. 2022

\begin{abstract}
Although the link from family economic strain to adolescent aggression has frequently been hypothesized, the results are mixed. Both interparental conflict and parent-child conflict are considered to be potential mediators of this link. However, the empirical evidence supporting this proposition is lacking. The present study investigated the direct effect of family economic strain on adolescent aggression as well as indirect effects through interparental conflict and parent-child conflict. Based on multi-informant data from 971 families with a child in middle and high schools in Y City, in Shanxi Province, structural equation modeling is conducted to examine the proposed theoretical model. Findings show that family economic strain has no significant direct impact on adolescent aggression. Interparental conflict and parent-child conflict mediate the link between family economic strain and adolescent aggression simultaneously and sequentially. This study expands current literature and deepens our understanding of the mechanisms underlying the relationship between family economic strain and adolescent aggression. Implications for policies and interventions to reduce the risk of adolescent aggression are discussed.
\end{abstract}

Keywords Family economic strain · Interparental conflict · Parent-child conflict · Adolescent aggression

Zhiyou Wang

wangzhiyounju@163.com

1 Department of Social Work, The Chinese University of Hong Kong, Hong Kong, China

2 School of Social and Behavioral Sciences, Nanjing University, Nanjing, China

3 Faculty of History, Nankai University, Tianjin, China 


\section{Introduction}

The Covid-19 pandemic has had a large economic impact worldwide and millions of children have been pushed further below the poverty line (Save the Children and UNICEF, 2020). Children raised in economically disadvantaged families are at a higher risk for engaging in problem behaviors (Berti \& Pivetti, 2019; Voisin et al., 2020), such as aggression (Baker et al., 2020). Especially for adolescents, several developmental changes during this period make them more susceptible to aggression (Yoon et al., 2004; Zimmer-Gembeck et al., 2014). Aggression is defined as a wide rage of behaviors that target another individuals and cause harm intentionally (Anderson \& Bushman, 2002). It can be manifested in many types, including physical aggression, verbal aggression, and displays of anger and hostility (Buss \& Perry, 1992). A growing body of studies has demonstrated that adolescent aggression adversely affect development, such as poor academic performance and subsequent psychological problems, delinquency and even crime (Chang et al., 2021; Vuoksimaa et al., 2021).

The empirical evidence on the relationship between family economic strain and youth aggression is mixed: some studies have found that family economic strain strongly predict adolescent aggression (Hong et al., 2020; Mazza et al., 2017), while others have found a weak or non-significant relationship (Jiang \& Dong, 2020; Kim \& Um, 2018). The mixed findings may be explained by variables that mediate the relationship between family economic strain and youth aggression. Some theories and perspectives (e.g., family stress model) have proposed that both interparental and parent-child conflict may be potential mediators between family economic strain and adolescent aggression (Conger et al., 2002; McLoyd \& Wilson, 1990), but empirical evidence is lacking. In addition, most of the previous studies on family economic strain are usually based solely on data from children, ignoring the importance of reports from parents (Jiang et al., 2018; Li et al., 2018). Children lack a comprehensive understanding of family economic strain, thus their reports may not reflect the real condition of their family economic strain, while parents are regarded as direct bearers of the family economic strain and perceive those pressure more accurately (Chen et al., 2020). In addition, children may also underreport conflicts with their parents because of social desirability (Benbenishty and Astor, 2005; Munsell et al., 2016), which can inflate the association between variables and reduce the validity of research findings (Boyer \& Verma, 2000; Gerard et al., 2006). Therefore, in order to address those shortcomings in previous research and increase research validity, the current study aims at simultaneously exploring the potential mediation roles of interparental conflict and parent-child conflict in the relationship of family economic strain with adolescent aggression using multi-informant data (parent report on family economic strain and parent-child conflict and child report on interparental conflict and aggression). 


\section{Literature Review}

\section{Family Economic Strain and Adolescent Aggression}

Economic strain is defined as an individual's subjective evaluation of his or her economic situation, rather than an objective assessment, including perceptions of financial resources and concerns, and expectations about future economic conditions (Voydanoff \& Donnelly, 1988). The link between family economic strain and aggression among adolescent has been hypothesized by several theories. For example, from the perspective of the general strain theory (Agnew, 1999, 2013), family economic strain can result in a series of negative emotions, such as anger and fear, which will increase the risk of maladaptive behaviors. That is, adolescents suffering from family economic strain are highly likely to engage in aggression to release relevant negative emotions. The family adjustment and adaptation response model also asserts that family stressors can reduce the family's ability to perceive resources and coping strategies (Patterson, 1988). Specifically, when parents or caregivers have to face some stressful events such as family economic strain, their ability to cope with the needs of children will be reduced, which increases the likelihood of them having behavior problems (Nebbitt et al., 2014; Voisin et al., 2016).

Although many theories consistently agree on the influence of family economic strain on adolescent aggression, the findings of empirical studies are controversial. For example, Mazza et al. (2017) found that family economic pressure was related to a higher likelihood of physical aggression. Children raised in impoverished families are often exposed to a series of risk factors (e.g., unemployed parents, disrupted parenting and single-parent status) that are related to a greater frequency of aggressive behavior (Baker et al., 2020; Qi \& Kaiser, 2003). However, one study conducted by Jiang and Dong (2020) showed that there is no significant direct effect of family economic pressure on juvenile aggression among Chinese middle and high school students. Kim and Um (2018) has also found the non-significant relationship between the two variables. Therefore, the link from family economic strain to adolescent aggression remain unclear.

\section{Interparental Conflict, Parent-Child Conflict and Adolescent Aggression}

There are several controversies regarding the nexus between interparental conflict and parent-child conflict: some theories proposes that interparental conflict and parent-child conflict is positively correlated and others support the negative relationship between them. Specifically, according to the spillover hypothesis (Zimet \& Jacob, 2001), interparental conflict can cause some emotional distress for both parents, which will deplete their emotional resources and reduce their sensitivity to the needs of their children. This can reduce parental social support for their children, and thus threat the relationship between parents and children (Erel \& Burman, 1995). Sherrill et al.(2017) found that parents who often engage in conflict with their spouse are highly likely to experience conflict with their children subsequently. A good relationship between husband and wife is conducive to reducing conflicts 
between parents and children (Li et al., 2020). However, some perspectives of the compensatory hypothesis (Engfer, 1988) have proposed that there may also be a negative correlation between marital conflict and parent-child conflict. In families with high level of interparental conflict, parents are inclined to meet their emotional needs from the relationship with their children as a compensation. Accordingly, interparental conflict may enhance the relationship between parents and children. This theoretical dispute remains unresolved, and an exploration of the link between the two types of conflict is appropriate.

Both conflicts between parents and between parents and children are risk factors for adolescent aggression. The standard family environment model (Amato \& Cheadle, 2008) assumes that family dysfunction characterized by marital conflict and parent-child conflict increases the risk of a variety of child behavioral problems, including aggression. When children witness conflicts between their parents, exposure to destructive conflict make children highly likely to engage in aggressive behavior (Cummings et al., 2004). Adolescent aggression is severely affected by coercive conflict between parents, because those conflicts shape children's conflict resolution strategies and unwittingly strengthen children's aggressive responses (Ingoldsby et al., 2006; Kazdin, 1992). In addition, some studies also support that parent-child conflicts cause the lack of effective communication and interaction between parents and children, and simultaneously reduce the level of parental support and attachment. Those changes contribute to the increased psychological pressure on children, which then increases the possibility of physical aggression (Iniewicz et al., 2011; Savage, 2014).

\section{Family Economic Strain, Interparental Conflict, Parent-Child Conflict and Adolescent Aggression}

Studies have shown that family economic strain is associated with interparental conflict and parent-child conflict (Letourneau et al., 2013; Rouchun et al., 2019; Shen et al., 2013). Parents who are suffering from family economic strain are more likely to experience negative emotions such as anger, fear, and frustration (Agnew, 1992). Due to frequent contact and communication with spouse and children, the resulting tension seems to have direct effect on them, which increases the probability of interparental conflict and parent-child conflict (Paat, 2011). For example, Nepplet al.(2016) found that parents living in a family with financial strain are increasingly likely to attack each other on financial issues, thereby increasing the risk of conflict between them. And compared with other marital conflicts, such economic disputes are longer lasting, more frequent, and are more difficult to resolve (Papp et al., 2009). In addition, family economic strain determines the material conditions and activities that parents can provide for their children (Rouchun et al., 2019). Families with low economic strain have more capital to invest in their children and more time to accompany them, thereby creating a good parent-child relationship (Shi et al., 2013). However, for families under high economic strain, because parents cannot meet the material needs of their children, conflicts between parents and children involving money are expected to occur (McLoyd \& Wilson, 1990). 
In summary, the controversy regarding the association between family economic strain and adolescent aggression implies that there may be a variety of potential mediating mechanisms underlying this relationship. Interparental conflict and parent-child conflict have been regarded as potential simultaneously and serial mediators of the link between family economic strain and adolescent aggression. There are two main theoretical and emprical arguments supporting this proposition. First, family economic strain can increase interparental conflict and parent-child conflict at the same time (Conger et al., 1993; Neppl et al., 2016), thereby increase the risk of adolescent aggression (Amato \& Cheadle, 2008; Bowlby, 2005). Second, family economic strain is hypothesized to predict increased interparental conflict and subsequently interparental conflict may negatively or positively affect parent-child interaction and communication. This in turn, can impact adolescent aggression (Conger et al., 2002; Cummings et al., 2004; Savage, 2014). However, there is a paucity of empirical evidence to support this proposed model.

\section{Method}

\section{Data}

Using multi-stage cluster random sampling method, all the participants (971 adolescents and one of their parents) were sampled from two middle schools (grades 7-9) and two high schools (grades 10-12) in Y City, in Shanxi Province in mainland China during the period from September to October 2020. Before the data collection, all adolescents and their parents signed an informed consent from. After the research assistants explained the instructions, adolescents completed the questionnaires in their classrooms. The parental part of the questionnaire was taken home by students to be completed by their father or mother and brought back to school the next day. The sample included 469 boys and 468 girls. With in this sample, $59 \%$ of the participants were left-behind children who stay in rural areas while their parents go to work in cities and $41 \%$ were non-left-behind children. In addition, in the sample of parents, mothers accounted for $76.6 \%$ and fathers accounted for $21.6 \%$. About half of the parents had finished middle school (42.5\% for fathers, $48.7 \%$ for mothers). The average annual income of the surveyed households is about RMB72,000, which is significantly lower than the national average of RMB120,000 in 2020. A large proportion of the fathers $(64 \%)$ were engaged in manual labour such as factory workers and more than half of the mothers $(55.2 \%)$ were unemployed (the national unemployment rate is $5.2 \%$ in 2020).

\section{Measurements}

\section{Family Economic Strain}

The Family Economic Strain Scale was used to assess family primary caregiver's (father or mother) perception of family economic strain (Hilton \& Devall, 1997). 
Because this scale had not been used in Chinese in previous studies, we translated it into Chinese based on the back-translation method. Specifically, we invite professional translators in this field to translate the completed translation back into the original language. Then we compared that new translation with the original version and reconciled any meaningful differences between the two. After confirmatory factor analysis, all the items were retained, as their factor loadings were greater than 0.4 (Brown, 2015; Harrington, 2009). Participants indicated how often they experienced a specific type of stress on a 5-point scale (from never to almost always), such as "I encounter money problems," "I worry about financial matters," and "I worry that there is no enough money to celebrate holidays and participate in other special occasions." Level of family economic strain was calculated by creating a mean value of the 13 items with higher scores indicating higher level of family economic strain. Previous studies have demonstrated that the scale had good internal consistency (Falconier, 2010; Rusu et al., 2018). In the present study, the Cronbach's $\alpha$ for the scale was 0.940 .

\section{Interparental Conflict}

The Children Perception of Interparental Conflict Scale was applied to assess interparental conflict (Grych et al., 1992). It is a 19-item scale with three subscales including conflict frequency, conflict intensity, and conflict resolution. Each item is rated on a 4-point scale from never to always. The average of all items in each subscale was calculated, with higher scores indicating higher levels of conflict frequency, intensity, and resolution, respectively. The conflict frequency subscale includes six items, such as "Even if my parents don't tell me, I know they are arguing" (factor loading $=0.860$ ). The conflict intensity subscale includes a total of seven items, such as "When my parents quarreled, they would start to fight each other" (factor loading $=0.884$ ). The conflict resolution subscale includes six items, for example, "When my parents have different opinions on something, they will come up with a solution" (factor loading $=0.765$ ). The reliability and validity of this scale in Chinese version were satisfactory in previous empirical studies (Wang et al., 2021; Yang et al., 2018). The Cronbach's $\alpha$ of the scale in this study was 0.913 .

\section{Parent-Child Conflict}

Family primary caregiver (father or mother) reported the level of conflict with their children using the conflict subscale of the Parental Environment Questionnaire (PEQ) (Elkins et al., 1997). Using the back-translation method, we translated this scale into Chinese, because it has not been used in China in previous studies. After conducting confirmatory factor analysis, one item was deleted because its factor loading was below 0.4, so as to increase research validity (Brown, 2015; Harrington, 2009). The remaining eleven items include, "I criticize my child," "I interrupt my child," "There are some misunderstandings between me and my child," "My child and I get into arguments," etc. Each item was rated on a 4-point scale from never to often. All eleven items were averaged and higher scores reflected higher level of parent-child conflict. This scale was demonstrated to have fair internal reliability and 
good validity in many previous studies (Klahr et al., 2011; Samek et al., 2018), and Cronbach' s $\alpha$ for the scale in present study was 0.900 .

\section{Adolescent Aggression}

The Buss-Perry Aggression Questionnaire was used to measure adolescent aggressive behavior in this study (Buss \& Perry, 1992). It is a self-report 29-item scale covering four dimensions: physical aggression, verbal aggression, anger and hostility. Ratings were completed on a 5-point scale from strongly disagree to strongly agree. The mean of all the items in each dimension were calculated with the higher score indicating higher level of aggression. The physical aggression subscale includes nine items (factor loading $=0.590$ ). The verbal aggression subscale includes five items (factor loading $=0.411$ ). The subscales for anger and hostility have seven and eight items (factor loading $=0.773$ for anger and factor loading $=0.711$ for hostility). The Chinese version of this scale has been proved to have good reliability and validity (Chen \& Qin, 2020; Xie et al., 2020). And the Cronbach's alpha of this scale is 0.872 in this study.

\section{Control Variables}

The analyses controlled for some sociodemographic variables, including grade ( from $0=$ first grade of middle school to $5=$ high school senior $)$, gender $(0=$ male; $1=$ female $), \quad$ left-behind status $\quad(0=$ left-behind children; $1=$ non-left-behind children).

\section{Analysis}

Descriptive statistics (means, standard deviations and correlations for the core variables) were computed in SPSS 21.0. Structural equation modeling including measurement modeling and structural modeling was carried out using Amos 24.0. First, confirmatory factor analysis was implemented to ensure that the measurement model had a good fit (Bentler, 1990), then structural modeling was carried out to examine direct and indirect effects of family economic strain on adolescent aggression. The following indices were employed to assess goodness of fit: the chi-square coefficient $\left(\chi^{2}\right)$, the comparative fit index (CFI), and the root mean square error of approximation (RMSEA). When CFI is above 0.90 and RMSEA is below 0.08, that indicates that the model fits data well (Hu \& Bentler, 1999; Kline, 2015). In order to further test the mediation effects, we conducted bootstrapping analyses with 2,000 bootstrapped samples and 95\% confidence intervals. The influence is judged to be significant if zero is not included within the interval scope (Preacher \& Hayes, 2008). In addition, gender, grade and left-behind children status were included as control variables in this study. 


\section{Results}

\section{Descriptive Statistics}

Table 1 shows the means, standard deviations, and bivariate correlations of core variables in this study. Among the four types of aggression, hostility had the highest mean score, followed by anger, then verbal aggression, and the lowest was physical aggression. Family economic strain was positively associated with all of the three dimensions of interparental conflict and parent-child conflict. Of the four types of aggression, only verbal aggression was not significantly related to family economic strain. Parent-child conflict was positively associated with interparental frequency, interparental intensify and interparental resolution. All the four types of aggression were positively correlated with parent-child conflict..

\section{Overall Model}

The results of the analysis showed a good fit to the data: $\chi^{2}=193.561, \mathrm{df}=43$, $\mathrm{p}<0.001, \mathrm{CFI}=0.947$, and RMSEA $=0.060$. The estimates of the structural model were presented in Table 2. Family economic strain was positively associated with interparental conflict, parent-child conflict, but not significantly directly associated with adolescent aggression. Both interparental conflict and parent-child conflict were significant predictors for adolescent aggression. Interparental conflict showed a remarkable effect on parent-child conflict. Table 3 showed the results of bootstrap for specific indirect effects. As can be seen, family economic strain had significant indirect effects on adolescent aggression through interparental conflict and parent-child conflict respectively. The results also found the significant mediating path from family economic strain to interparental conflict to parent-child conflict to adolescent aggression.

In summary, interparental conflict and parent-child conflict fully mediated the association between family economic strain and adolescent aggression. The standardized solution for the structural model was exhibited in Fig. 1. All the variables in this study accounted for $23.3 \%$ of the explained variance in adolescent aggression. In addition, gender was the only control variable significantly related to interparental conflict, which suggests that the family with girls may have more interparental conflicts. Grade was positively related with adolescent aggression, which indicates that students in higher grades are more likely to engage in aggressive behavior than students in lower grades.

\section{Discussion}

Based on a random sample in Y City, in Shanxi Province, this study explored the direct and indirect effects of family economic strain on adolescent aggression by examining the potential mediators of interparental conflict and parent-child conflict 


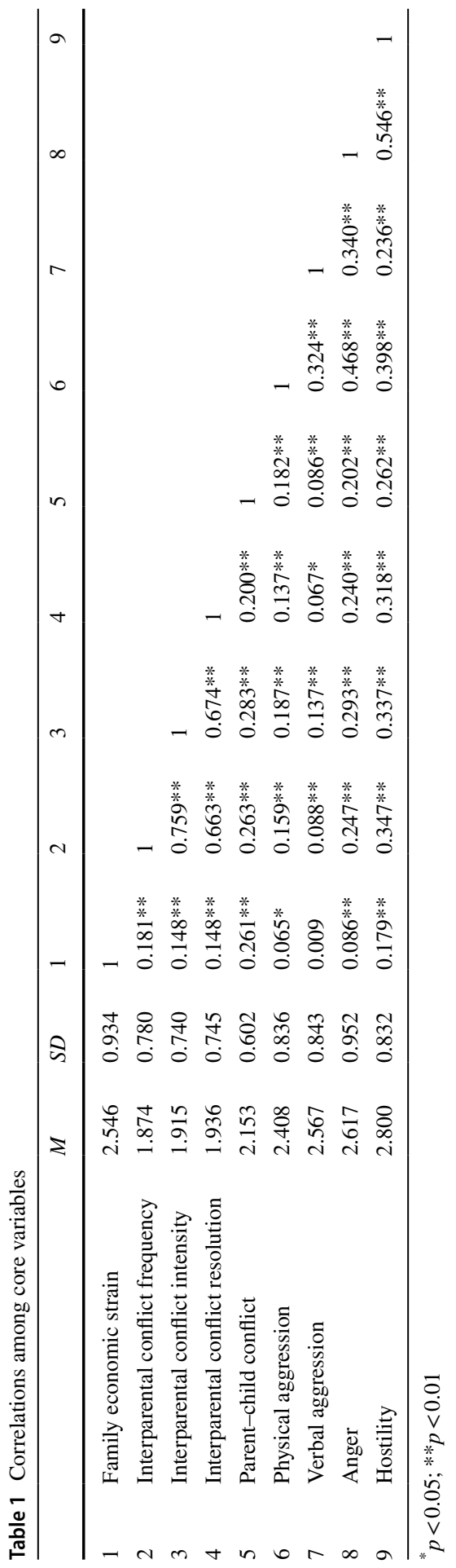


Table 2 Estimates of the structural model

\begin{tabular}{lllll}
\hline & $B$ & $\beta$ & $S E$ & $p$ \\
\hline Interparental conflict $\leftarrow$ Family economic strain & 0.134 & 0.168 & 0.025 & $* * *$ \\
Parent-child conflict $\leftarrow$ Interparental conflict & 0.239 & 0.266 & 0.030 & $* * *$ \\
Parent-child conflict $\leftarrow$ Family economic strain & 0.140 & 0.216 & 0.020 & $* * *$ \\
Aggression $\leftarrow$ Parent-child conflict & 0.145 & 0.178 & 0.031 & $* * *$ \\
Aggression $\leftarrow$ Family economic strain & 0.018 & 0.035 & 0.019 & 0.331 \\
Aggression $\leftarrow$ Interparental conflict & 0.268 & 0.365 & 0.031 & $* * *$ \\
Interparental conflict $\leftarrow$ Grade & 0.013 & 0.038 & 0.012 & 0.267 \\
Interparental conflict $\leftarrow$ Gender & 0.089 & 0.075 & 0.040 & $*$ \\
Interparental conflict $\leftarrow$ Left-behind status & 0.007 & 0.005 & 0.047 & 0.876 \\
Parent-child conflict $\leftarrow$ Grade & -0.006 & -0.018 & 0.010 & 0.556 \\
Parent-child conflict $\leftarrow$ Gender & -0.010 & -0.009 & 0.032 & 0.759 \\
Parent-child conflict $\leftarrow$ Left-behind status & 0.036 & 0.029 & 0.038 & 0.344 \\
Aggression $\leftarrow$ Grade & 0.024 & 0.091 & 0.009 & $* *$ \\
Aggression $\leftarrow$ Gender & 0.026 & 0.029 & 0.030 & 0.384 \\
Aggression $\leftarrow$ Left-behind status & 0.037 & 0.037 & 0.035 & 0.288 \\
\hline
\end{tabular}

$B=$ unstandardized path coefficient; $\beta=$ standardized path coefficient; $S E=$ standard error; $p=$ significance level. *** $p<0.001 ; * * p<0.01 ; * p<0.05$

Table 3 Bootstrap results for specific indirect effects

\begin{tabular}{|c|c|c|c|c|c|}
\hline \multirow[b]{2}{*}{ Effects } & \multirow[b]{2}{*}{$\beta$} & \multirow[b]{2}{*}{$S E$} & \multirow[b]{2}{*}{$p$} & \multicolumn{2}{|l|}{$95 \% \mathrm{CI}$} \\
\hline & & & & Lower & Upper \\
\hline Aggression $\leftarrow$ Interparental conflict $\leftarrow$ Family economic strain & 0.036 & 0.008 & 0.001 & 0.036 & 0.053 \\
\hline Aggression $\leftarrow$ Parent-child conflict $\leftarrow$ Family economic strain & 0.020 & 0.005 & 0.001 & 0.011 & 0.033 \\
\hline $\begin{array}{l}\text { Aggression } \leftarrow \text { Parent-child conflict } \leftarrow \text { Interparental conflict } \\
\leftarrow \text { Family economic strain }\end{array}$ & 0.003 & 0.001 & 0.001 & 0.001 & 0.006 \\
\hline
\end{tabular}

$\beta=$ standardized coefficient; $S E=$ standard error; $p=$ significance level; $\mathrm{CI}=$ confidence interval

simultaneously, using a multi-informant approach (parent report on family economic strain and parent-child conflict and child report on interparental conflict and aggression). Although the results did not support the direct effect of family economic strain on adolescent aggression, interparental conflict and parent-child conflict both simultaneously and sequentially mediated the association between family economic strain and adolescent aggression. The specific results are dicussed in following paragraphs.

We found that family economic strain had no significant direct effect on adolescent aggression. The finding is inconsistent with the family adjustment and adaptation response model which hypothesizes that family stressors can increase the risk of children behevioral problems (Patterson, 1988). Specifically, family with economic strain will encounter the reduced ability of perceiving resources and coping strategies. Once those capacity declines, children's needs in the family may be coped 


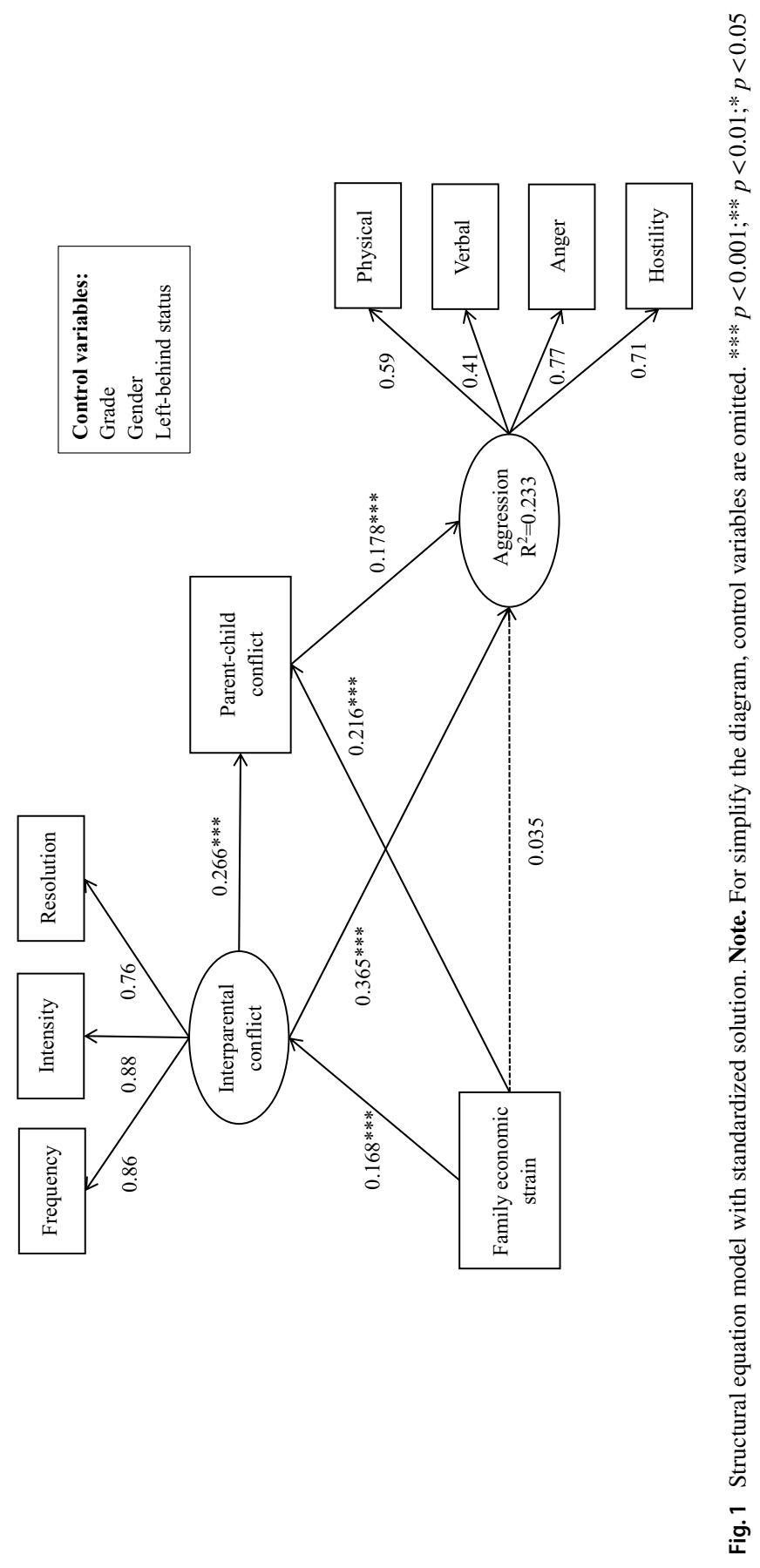


less well, thereby increasing the risk of their aggression (Nebbitt et al., 2014; Voisin et al., 2016). But the finding is in line with some previous empirical studiese (Jiang \& Dong, 2020; Kim \& Um, 2018) that showed non-significant relationship between family economic strain and adolescent aggression. One possible explanation is that children are not particularly aware of the real economic situation of the family (Munsell et al., 2016). And family economic strain is mainly borne by the parents, while children's perception of family economic strain is relatively weak, because in many relatively poor families, parents usually sacrifice their own needs so as to ensure their children's material needs are met (Ogwumike \& Ozughalu, 2018). In such households, it is difficult for children to intuitively feel family economic strain, and the influence of family economic strain on behavior will be very weak. In addition, the study suggests the positive association between interparental conflict and parent-child conflict, which is consistent with the findings of most of previous studies (Li et al., 2020; Sherrillet al., 2017). One possible explanation is that interparental conflict can increase parental emotional distress, which will reduce their sensitivity to the needs of their children, and reduce their social support for their children, therefore causing the relationship between parents and children to deteriorate (Erel \& Burman, 1995; Zimet \& Jacob, 2001).

Moreover, the findings show that interparental conflict and parent-child conflict simultaneously mediate the relationship of family economic strain with adolescent aggression, which is congruent with previous assumptions. Parents living in economically stressed families are more likely not only to experience interparental conflict, but also to have more conflicts with their children regarding the distribution and use of limited financial resources (Letourneau et al., 2013; Rouchun et al., 2019). And both interparental conflict and parent-child conflict increase the risk of adolescent aggression (Amato \& Cheadle, 2008; Bowlby, 2005). Furthermore, consistent with the family stress model (Conger et al., 2002), we also found that interparental conflict and parent-child conflict work as serial mediators of the link between family economic strain and juvenile aggression. That is, parents in families with high economic strain are more likely to experience interparental conflict, which is associated with parent-child conflict, thereby increasing the likelihood of children's aggressive behavior. The findings of this study highlight the important roles played by family interaction processes, including the conflict between parents and between parent and children, in the relationship between family economic strain and adolescent aggression, and imply that there may be other potential family process underlying this relationship that deserve to be explored. For example, family system theory (Cox \& Paley, 2003) proposes the mutual influences among family subsystems. Interparental conflict could produce effects on the other family system that feed back into the family system again.

\section{Implications}

At the theoretical level, this study extended the knowledge by testing the indirect effect of family economic strain on adolescent aggression through interparental conflict and parent-child conflict based on multi-informant data from parents and 
children simultaneously. This theoretical framework potentially could also apply to other groups and cultural contexts to examine the relationship between family economic strain and adolescent aggression. In addition, the results spoke to the divergence of results of previous studies regarding the association between family economic strain and adolescent aggression and indicated that Chinese adolescents' aggressive behavior was not directly affected by family economic strain and some family interaction process played important roles underlying this link. The question if a positive or negative correlation between interparental conflict and parent-child conflict was also addressed by the results of this research. Moreover, the study also examined the reliability and validity of the Family Economic Strain Scale and the conflict subscale of the Parental Environment Questionnaire in the Chinese cultural context, which is helpful for the application of the two scales in China.

At the practical level, the present study indicated that the serial indirect effect of family economic strain on adolescent aggression through both interparental conflict and parent-child conflict was significant. Thus, in order to reduce the risk of adolescent aggression more efficiently, social work interventions should focus on creating harmonious family interactions. Parents need to be educated about the interdependence between the various family subsystems such as the interaction between the parental system and the parent-child system (van Dijk et al., 2020). Some interventions such as brief psychological education can be adopted to teach families constructive methods of addressing conflicts, which have been shown to have a positive impact on children development (Miller-Graff et al., 2016). Social workers can assist children in adopting coping strategies on interparental conflicts and parent-child conflicts, which may help reduce their risk of aggression (Silva et al., 2020). In addition, although the findings showed a non-significant direct effect of family economic strain on adolescent aggression, family economic strain can indirectly influence adolescent aggression by increasing family conflict. Thus, policymakers should also focus on reducing family economic strain. It is important to solve the problem of unemployment and housing, and increase family income (Berti \& Pivetti, 2019). A series of programs, such as family economic support and parenting programs, could be used to attenuate the risk of externalizing behaviors in adolescents (Fergusson et al., 2004).

\section{Limitations}

There are several noteworthy limitations of present study. First, this study used a cross-sectional survey data, which cannot be used to identify the causal relationships among family economic strain, interparental conflict, parent-child conflict and adolescent aggression. Future research should examine this issue via a longitudinal design that allows for causal inferences. Second, most of the parents of this study are mothers; fathers only accounts for a small percentage of the whole sample of parents. Future studies should include more father data, or collect data from both parents for the same variable so as to increase research validity. Third, in the present study, we only controlled grade, gender and left-behind status in the analysis. Other important potential influencing factors, such as delinquent peer affiliation and 
community conditions, should be taken into consideration in future studies (Jiang \& Dong, 2020). Finally, the study used a random sample from two middle schools and two high schools in Y City, in Shanxi Province, so caution should be exercised in generalization this study's findings to other groups and cultural contexts. Future studies should aim to replicate this study in other groups and areas so as to have a comprehensive understanding of these relationships among family economic strain, interparental conflict, parent-child conflict, and adolescent aggression.

\section{References}

Agnew, R. (1999). A general strain theory of community differences in crime rates. Journal of Research in Crime \& Delinquency, 36(2), 123-155. https://doi.org/10.1177/0022427899036002001

Agnew, R. (2013). When criminal coping is likely: An extension of general strain theory. Deviant Behavior, 34, 653-670. https://doi.org/10.1080/01639625.2013.766529

Amato, P. R., \& Cheadle, J. E. (2008). Parental divorce, marital conflict and children's behavior problems: A comparison of adopted and biological children. Social Forces, 86(3), 1139-1161. https:// doi.org/10.1353/sof.0.0025

Anderson, C. A., \& Bushman, B. J. (2002). Human aggression. Annual Review of Psychology, 53, $27-51$. https://doi.org/10.1146/annurev.psych.53.100901.135231

Baker, E. R., Jensen, C. J., Moeyaert, M., \& Bordoff, S. (2020). Socioeconomic status and early childhood aggression: Moderation by theory of mind for relational, but not physical, aggression. Early Child Development and Care, 190(8), 1187-1201. https://doi.org/10.1080/03004430.2018.1524379

Benbenishty, R., \& Astor, R. A. (2005). School violence in context: Culture, neighborhood, family school, and gender. Oxford University Press.

Bentler, P. M. (1990). Comparative fit indexes in structural models. Psychological Bulletin, 107(2), 238-246.

Berti, C., \& Pivetti, M. (2019). Childhood economic disadvantage and antisocial behavior: Intervening factors and pathways. Children and Youth Services Review, 97, 120-126. https://doi.org/10.1016/j. childyouth.2017.06.007

Boyer, K. K., \& Verma, R. (2000). Multiple raters in survey-based operations management research: A review and tutorial. Production and Operations Management, 9(2), 128-140. https://doi.org/10. 1111/j.1937-5956.2000.tb00329.x

Brown, T. A. (2015). Confirmatory factor analysis for applied research. Guilford Press.

Buss, A. H., \& Perry, M. (1992). The aggression questionnaire. Journal of Personality and Social Psychology, 63(3), 452-459.

Chang, S., Hou, Q., Wang, C., Wang, M., Wang, L., \& Zhang, W. (2021). Childhood maltreatment and violent delinquency in Chinese juvenile offenders: Callous-unemotional traits as a mediator. Child Abuse \& Neglect, 117, 105085. https://doi.org/10.1016/j.chiabu.2021.105085

Chen, C., \& Qin, J. (2020). Childhood physical maltreatment and aggression among chinese young adults: The roles of resilience and self-esteem. Journal of Aggression, Maltreatment \& Trauma, 29(9), 1072-1091. https://doi.org/10.1080/10926771.2019.1699217

Chen, J. K., Wu, C., \& Wei, H. S. (2020). Personal, family, school, and community factors associated with student victimization by teachers in Taiwanese junior high schools: A multi-informant and multilevel analysis. Child Abuse \& Neglect, 99, 104246. https://doi.org/10.1016/j.chiabu.2019. 104246

Conger, R. D., Lorenz, F. O., Elder, G. H., Jr., Simons, R. L., \& Ge, X. (1993). Husband and wife differences in response to undesirable life events. Journal of Health and Social Behavior, 34, 71-88. https://doi.org/10.2307/2137305

Conger, R. D., Wallace, L. E., Sun, Y., Simons, R. L., Mcloyd, V. C., \& Brody, G. H. (2002). Economic pressure in african american families: A replication and extension of the family stress model. Developmental Psychology, 38(2), 179-193. https://doi.org/10.1037/0012-1649.38.2.179

Cox, M. J., \& Paley, B. (2003). Understanding families as systems. Current Directions in Psychological Science, 12(5), 193-196. 
Cummings, E. M., Goeke-Morey, M. C., \& Papp, L. M. (2004). Everyday marital conflict and child aggression. Journal of Abnormal Child Psychology, 32(2), 191-202. https://doi.org/10.1023/B: JACP.0000019770.13216.be

de Silva, A. D., Gao, M. M., Barni, D., Donato, S., Miller-Graff, L. E., \& Cummings, E. M. (2020). Interparental conflict on Italian adolescent adjustment: The role of insecurity within the family. Journal of Family Issues, 42(3), 671-692. https://doi.org/10.1177/0192513X20927749

Elkins, I. J., Mcgue, M., \& Iacono, W. G. (1997). Genetic and environmental influences on parent-son relationships: Evidence for increasing genetic influence during adolescence. Developmental Psychology, 33(2), 351. https://doi.org/10.1037//0012-1649.33.2.351

Engfer, A. (1988). The interrelatedness of marriage and the mother-child relationship. Relationships within Families: Mutual Influences, 7, 104.

Erel, O., \& Burman, B. (1995). Interrelatedness of marital relations and parent-child relations: A metaanalytic review. Psychological Bulletin, 118(1), 108-132. https://doi.org/10.1037/0033-2909.118.1. 108

Falconier, M. K. (2010). Female anxiety and male depression: Links between economic strain and psychological aggression in Argentinean couples. Family Relations, 59(4), 424-438. https://doi.org/10. 1111/j.1741-3729.2010.00613.x

Fergusson, D., Swain-Campbell, N., \& Horwood, J. (2004). How does childhood economic disadvantage lead to crime? Journal of Child Psychology and Psychiatry, 45(5), 956-966. https://doi.org/10. 1111/j.1469-7610.2004.t01-1-00288.x

Gerard, J. M., Krishnakumar, A., \& Buehler, C. (2006). Marital conflict, parent-child relations, and youth maladjustment: A longitudinal investigation of spillover effects. Journal of Family Issues, 27(7), 951-975. https://doi.org/10.1177/0192513X05286020

Grych, J. H., Seid, M., \& Fincham, F. D. (1992). Assessing marital conflict from the child's perspective: The Children's Perception of Interparental Conflict Scale. Child Development, 63(3), 558-572. https://doi.org/10.1111/j.1467-8624.1992.tb01646.x

Harrington, D. (2009). Confirmatory factor analysis. Oxford University Press.

Hilton, J. M., \& Devall, E. L. (1997). The Family Economic Strain Scale: Development and evaluation of the instrument with single-and two-parent families. Journal of Family and Economic Issues, 18(3), 247-271. https://doi.org/10.1023/A:1024974829218

Hong, J. S., Kim, D. H., Narvey, C., Piquero, A. R., deLara, E., \& Padilla, Y. C. (2020). Understanding the link between family economic hardship and children's bullying behavior. Youth \& Society. https://doi.org/10.1177/0044118X20932594

Hu, L. T., \& Bentler, P. M. (1999). Cutoff criteria for fit indexes in covariance structure analysis: Conventional criteria versus new alternatives. Structural Equation Modeling: A Multidisciplinary Journal, 6(1), 1-55. https://doi.org/10.1080/10705519909540118

Ingoldsby, E. M., Shaw, D. S., Winslow, E., Schonberg, M., Gilliom, M., \& Criss, M. M. (2006). Neighborhood disadvantage, parent-child conflict, neighborhood peer relationships, and early antisocial behavior problem trajectories. Journal of Abnormal Child Psychology, 34(3), 293-309. https://doi. org/10.1007/s10802-006-9026-y

Iniewicz, G., Wiśniewska, D., Dziekan, K., \& Czuszkiewicz, A. (2011). Attachment patterns and aggressive behaviours in adolescents suffering from mixed disorders of conduct and emotions. Psychiatria Polska, 45(5), 703-711.

Jiang, S., \& Dong, L. (2020). Social control and self-control: A serial mediation model from economic hardship to juvenile aggression. Journal of Interpersonal Violence. https://doi.org/10.1177/08862 60520948152

Jiang, S., Li, C., \& Fang, X. (2018). Socioeconomic status and children's mental health: Understanding the mediating effect of social relations in Mainland China. Journal of Community Psychology, 46(2), 213-223. https://doi.org/10.1002/jcop. 21934

Kazdin, A. E. (1992). Overt and covert antisocial behavior: Child and family characteristics among psychiatric inpatient children. Journal of Child and Family Studies, 1, 3-20. https://doi.org/10.1007/ BF01321339

Kim, D. H., \& Um, M. Y. (2018). The relationships among family income, parental depression, and adolescent aggression in South Korea: A latent growth mediation model. Children and Youth Services Review, 84, 168-175. https://doi.org/10.1016/j.childyouth.2017.11.025

Klahr, A. M., Mcgue, M., Iacono, W. G., \& Burt, S. A. (2011). The association between parent-child conflict and adolescent conduct problems over time: Results from a longitudinal adoption study. Journal of Abnormal Psychology, 120(1), 46-56. https://doi.org/10.1037/a0021350 
Kline, R. B. (2015). Principles and practice of structural equation modeling. Guilford publications.

Letourneau, N. L., Duffett-Leger, L., Levac, L., Watson, B., \& YoungMorris, C. (2013). Socioeconomic status and child development: A meta-analysis. Journal of Emotional and Behavioral Disorders, 21(3), 211-224. https://doi.org/10.1177/1063426611421007

Li, C., Jiang, S., Fan, X., \& Zhang, Q. (2020). Exploring the impact of marital relationship on the mental health of children: Does parent-child relationship matter? Journal of Health Psychology, 25(1011), 1669-1680. https://doi.org/10.1177/1359105318769348

Li, C., Liang, Z., Yin, X., \& Zhang, Q. (2018). Family social capital mediates the effect of poverty on children's anxiety and depression. Journal of Community Psychology, 46(8), 983-995. https://doi. org/10.1002/jcop. 22086

Mazza, J. R., Pingault, J. B., Booij, L., Boivin, M., Tremblay, R., Lambert, J., \& Côté, S. (2017). Poverty and behavior problems during early childhood: The mediating role of maternal depression symptoms and parenting. International Journal of Behavioral Development, 41(6), 670-680. https://doi. org/10.1177/0165025416657615

McLoyd, V. C., \& Wilson, L. (1990). Maternal behavior, social support, and economic conditions as predictors of distress in children. New Directions for Child and Adolescent Development, 1990(46), 49-69. https://doi.org/10.1002/cd.23219904605

Miller-Graff, L., Cummings, E. M., \& Bergman, K. N. (2016). Effects of a brief psychoeducational intervention for family conflict: Constructive conflict, emotional insecurity and child adjustment. Journal of Abnormal Child Psychology, 44(7), 1399-1410. https://doi.org/10.1007/s10802-015-0102-z

Munsell, E. P., Kilmer, R. P., Vishnevsky, T., Cook, J. R., \& Markley, L. M. (2016). Practical disadvantage, socioeconomic status, and psychological well-being within families of children with severe emotional disturbance. Journal of Child and Family Studies, 25(9), 2832-2842. https://doi.org/10. 1007/s10826-016-0449-y

Nebbitt, V., Tirmazi, T. M., Lombe, M., Cryer-Coupet, Q., \& French, S. (2014). Correlates of the sex trade among African-American youth living in urban public housing: Assessing the role of parental incarceration and parental substance use. Journal of Urban Health, 91(2), 383-393.

Neppl, T. K., Senia, J. M., \& Donnellan, M. B. (2016). Effects of economic hardship: Testing the family stress model over time. Journal of Family Psychology, 30(1), 12. https://doi.org/10.1037/fam00 00168

Ogwumike, F. O., \& Ozughalu, U. M. (2018). Empirical evidence of child poverty and deprivation in Nigeria. Child Abuse \& Neglect, 77, 13-22. https://doi.org/10.1016/j.chiabu.2017.12.019

Paat, Y. F. (2011). The link between financial strain, interparental discord and children's antisocial behaviors. Journal of Family Violence, 26(3), 195-210. https://doi.org/10.1007/s10896-010-9354-0

Papp, L. M., Cummings, E. M., \& Goeke-Morey, M. C. (2009). For richer, for poorer: Money as a topic of marital conflict in the home. Family Relations, 58, 91-103. https://doi.org/10.1111/j.1741-3729. 2008.00537.x

Patterson, J. M. (1988). Families experiencing stress: I. The Family Adjustment and Adaptation Response Model: II. Applying the FAAR Model to health-related issues for intervention and research. Family Systems Medicine, 6(2), 2023.

Preacher, K. J., \& Hayes, A. F. (2008). Asymptotic and resampling strategies for assessing and comparing indirect effects in multiple mediator models. Behavior Research Methods, 40(3), 879-891. https:// doi.org/10.3758/BRM.40.3.879

Qi, C. H., \& Kaiser, A. P. (2003). Behavior problems of preschool children from low-income families. Topics in Early Childhood Special Education, 23, 188-216. https://doi.org/10.1177/0271121403 0230040201

Rouchun, D., Zongkui, Z., Shuailei, L., Qingqi, L., \& Chen, G. (2019). Family socioeconomic status and the parent-child relationship: Children's Internet use as a moderated mediator. Current Psychology. https://doi.org/10.1007/s12144-019-00356-0

Rusu, P. P., Hilpert, P., Falconier, M., \& Bodenmann, G. (2018). Economic strain and support in couple: The mediating role of positive emotions. Stress and Health, 34(2), 320-330. https://doi.org/10.1002/ smi.2794

Samek, D. R., Wilson, S., McGue, M., \& Iacono, W. G. (2018). Genetic and environmental influences on parent-child conflict and child depression through late adolescence. Journal of Clinical Child \& Adolescent Psychology, 47(sup1), S5-S20. https://doi.org/10.1080/15374416.2016.1141357

Save the Children, UNICEF, 2020. Children in monetary poor households and COVID-19: Technical Note. Available from: https://www.unicef.org/media/69656/file/TechnicalNote-Children-living-inmonetary-poor-households-and-COVID-19.pdf. Accessed 25 Nov 2020. 
Savage, J. (2014). The association between attachment, parental bonds and physically aggressive and violent behavior: A comprehensive review. Aggression and Violent Behavior, 19(2), 164-178. https:// doi.org/10.1016/j.avb.2014.02.004

Sherrill, R. B., Lochman, J. E., DeCoster, J., \& Stromeyer, S. L. (2017). Spillover between interparental conflict and parent-child conflict within and across days. Journal of Family Psychology, 31(7), 900-909. https://doi.org/10.1037/fam0000332

Shen, C. X., Liu, R. D., \& Wang, D. (2013). The relationship between internet use and Children's loneliness_-A moderating effect of personality. Journal of Psychological Science, 36(5), 1140-1145.

Shi, L. S., Chen, Y. M., \& Gao, F. Q. (2013). Social economic status and study engagement: The mediating effects of academic self-efficacy among junior high school students. Psychological Development \& Education, 1, 71-78.

van Dijk, R., van der Valk, I. E., Deković, M., \& Branje, S. J. (2020). A meta-analysis on interparental conflict, parenting, and child adjustment in divorced families: Examining mediation using metaanalytic structural equation models. Clinical Psychology Review, 79, 0272-7358. https://doi.org/10. 1016/j.cpr.2020.101861

Voisin, D. R., Elsaesser, C., Kim, D. H., et al. (2016). The relationship between family stress and behavioral health among African American adolescents. Journal of Child and Family Studies, 25(7), 2201-2210. https://doi.org/10.1007/s10826-016-0402-0

Voisin, D. R., Kim, D. H., Bassett, S. M., \& Marotta, P. L. (2020). Pathways linking family stress to youth delinquency and substance use: Exploring the mediating roles of self-efficacy and future orientation. Journal of Health Psychology, 25(2), 139-151. https://doi.org/10.1177/1359105318763992

Voydanoff, P., \& Donnelly, B. W. (1988). Economic distress, family coping, and quality of family life. In P. Voydanoff \& L. C. Majka (Eds.), Families and economic distress: Coping strategies and social policy. New perspectives on family (pp. 97-115). Sage.

Vuoksimaa, E., Rose, R. J., Pulkkinen, L., Palviainen, T., Rimfeld, K., Lundström, S., \& Kaprio, J. (2021). Higher aggression is related to poorer academic performance in compulsory education. Journal of Child Psychology and Psychiatry, 62(3), 327-338. https://doi.org/10.1111/jcpp.13273

Wang, M., Xu, Q., \& He, N. (2021). Perceived interparental conflict and problematic social media use among Chinese adolescents: The mediating roles of self-esteem and maladaptive cognition toward social network sites. Addictive Behaviors, 112, 106601. https://doi.org/10.1016/j.addbeh.2020. 106601

Xie, Q., Bi, T., Du, Y., Kou, H., \& Yang, B. (2020). Childhood maltreatment is associated with aggression among male juvenile delinquents in China: The mediating effects of callous-unemotional traits and self-control. Frontiers in Psychology, 11, 1373. https://doi.org/10.3389/fpsyg.2020.01373

Yang, X., Wang, Z., Chen, H., \& Liu, D. (2018). Cyberbullying perpetration among Chinese adolescents: The role of interparental conflict, moral disengagement, and moral identity. Children and Youth Services Review, 86, 256-263. https://doi.org/10.1016/j.childyouth.2018.02.003

Yoon, J. S., Barton, E., \& Taiariol, J. (2004). Relational aggression in middle school educational implications of developmental research. The Journal of Early Adolescence, 24, 303-318. https://doi.org/10. $1177 / 0272431604265681$

Zimet, D. M., \& Jacob, T. (2001). Influences of marital conflict on child adjustment: Review of theory and research. Clinical Child and Family Psychology Review, 4(4), 319-335. https://doi.org/10. 1023/A:1013595304718

Zimmer-Gembeck, M. J., Trevaskis, S., Nesdale, D., \& Downey, G. A. (2014). Relational victimization, loneliness and depressive symptoms: Indirect associations via self and peer reports of rejection sensitivity. Journal of Youth and Adolescence, 43, 568-582. https://doi.org/10.1007/s10964-013-9993-6

Publisher's Note Springer Nature remains neutral with regard to jurisdictional claims in published maps and institutional affiliations. 